\title{
Distribution coefficient Kd of transuranics in soils: Experimental determination and consequences for dose assessment
}

\author{
S. Roussel-Debet and K. Beaugelin-Seiller \\ Institute of Protection and Nuclear Safety, DPRE/SERLAB, \\ Laboratory of Experimental Radioecology, Cadarache, \\ battiment 186, BP. 1, 13108 Saint-Paul-lez-Durance cedex, France
}

\begin{abstract}
Abatract. The distribution coefficient (or $\mathrm{Kd}$ ) of ${ }^{241}$ Am between soil and soil solution was estimated on the basis of experiments carried out under controlled conditions for soils displaying pH and organic matter content (which are the relevant parameters for transuranic nuclides sorption ability) found in cultivated soils. In these experiments, designed with five experimental units (batches) per studied contact time. $10 \mathrm{~g}$ of dry soil are contaminated with 50 $\mathrm{mL}$ of osmosed water containing proper concentrations of the radionuclide. The tracer, initially in nitric form, is neutralized prior to addition with the water, to ensure a constant ionic strength and a void disturbance of the soil chemistry. After shaking and sedimentation, for each batch, the supernatant is sampled and analyzed by either liquid scintillation or alpha spectronetry. The sorption-desorption kinetic time necessary to reach apparent equilibrium is evaluated ( $>10$ days). Fixation curves, e.g. activity of the soil $w s$ activity of the solution are established, after measurements. for a single delay representative of the equilibrium, and for a range of several orders of magnitude for radionuclide concentrations. On the basis of several assumptions, $\mathrm{Kd}$ values are evaluated by simple linear adjustment. A numerical application to retention half lives in soil is made. Finally, the weight of using site-specific $\mathrm{Kd}$ values instead of default parameters, on the doses due to ingestion of terrestrial foodstuffs is discussed for different scenarios.
\end{abstract}

\section{GENERAL SCOPE}

Many researches have improved the knowledge of the mechanisms relevant to the mobility of transuranians in the geosphere, aiming at better wastes disposals impact assessments [1-5]. In surface soils americium, usually trivalent and thus expected to have a simple behaviour by comparison with multivalency elements, is still far from being completely elucidated [6,7]; its mobility, connected with the formation of mobile species, either with soluble organic species [8-13] or with small clay particles, producing pseudo-colloids $[14,15]$, is particularly weak. Indeed, because of various phenomena such as hydrolysis, adsorption on clay particles, complexation with carbonates and with most of the humic substances, it tends predominantly to be strongly retained in the upper kevels of the soil [8, 16-17]. Although numerous studies have been focused on the sorption desorption processes of transuranics in soil, showing the influence of the global soil-solution parameters such as organics or $\mathrm{pH}$, only few experiments have determined distribution (or partition) coefficients $\mathrm{Kd}$ for agricultural soils. The $\mathrm{Kd}$ is defined as the ratio of the quantity of the contaminant adsorbed per unit mass of soil to the amount of the contaminant remaining in solution at equilibrium, and is currently expressed in $\mathrm{m}^{3}$ of solute per $\mathrm{kg}$ of dry soil. It is usually obtained from different methods including the laboratory batch or flow-through methods or by field modelling methods. The batch measurement is likely the most simple, yet least robust 
experimental pattern available. Also, while heterogeneity does typically exist in nature, the Kd value is only valid for the specific set of chemical conditions in which it was measured. In addition, the hypothesis that a) the soil-solute system is at reversible equilibrium and b) adsorption of the radionuclide is independent of its concentration in the aqueous phase are inherent assumptions in this approach, though basically violated. Additionally, values for $\mathrm{Kd}$ vary with aqueous and solid phase chemistry in the experiment as well as with several other experimental conditions such as the solution-to-solid ratio, the ionic strength or the impracticality of differentiating between soluble species of the radionuclides that may greatly affect the whole $\mathrm{Kd}$ value. Thus, it is not surprising that $\mathrm{Kd}$ values measured by different methods or with various experimental conditions will produce very dispersed data. Generic ${ }^{241} \mathrm{Am}-\mathrm{Kd}$ used for screening calculations range from about 1 in sandy soils to 110 in organic substrates [19], with lower and upper data being respectively 0.01 to 33000 . The common observed trend is a positive correlation of $\mathrm{Kd}$ with the organic matter content, for soil having a high (>25\%) organic matter content. For most soils, with mean or low organic matter content, a positive correlation between the soil $\mathrm{pH}$ and the sorption intensity is generally observed [18-20]. This apparent relationship does not clearly presume the actual sorption process, which may be controlled by any other soil parameter co-varying with $\mathrm{pH}$. Although these generic values may be useful, they are rather misappropriated for biosphere safety assessment, because data were mainly determined for geosphere, and also for the reason that they largely derive from rather extreme soils or even pure mineral phases. Furthermore, the high uncertainty associated with these $\mathrm{Kd}$ values results in a large variability of the predicted residence half-time in the upper layer of the soil, and of the subsequent estimated doses. Our experimental work aimed at such a determination, on seven agricultural soils exhibiting different physico-chemical properties.

\section{EXPERIMENTAL DETERMINATION OF KD}

\subsection{Soils}

Among the seven soils (Ap horizons) used, six are commonly found in French agricultural landscapes, and have rather mean properties as regard to $\mathrm{pH}$, organic matter content, texture, cationic complex saturation; an additional tropical cultivated soil (TH1), which has a specific high matter content and no mineralogical clay was also used as a comparison point.

Table I: Main characteristics of the tested soils (Values given as $\mathrm{g} \mathrm{kg}^{-1}{ }_{\text {dry sieved sai }}$ unless other precision).

\begin{tabular}{|c|c|c|c|c|c|c|c|}
\hline & CADO1 & LHAO1 & PAL01 & TRIO1 & BEILO1 & NCYOI & THI \\
\hline Rough sand & 7 & 23 & 2 & 3 & 73 & 9 & 13 \\
\hline Fine sand & 32 & 22 & 43 & 16 & 7 & 4 & 8 \\
\hline Rough silt & 25 & 22 & 39 & 21 & 6 & 18 & 6 \\
\hline Fine silt & 19 & 16 & 9 & 30 & 8 & 36 & 38 \\
\hline Clay & 17 & 18 & 7 & 30 & 6 & 33 & 35 \\
\hline O.M. & 37 & 71 & 11 & 32 & 15 & 31 & 340 \\
\hline 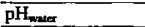 & 8.4 & 5.6 & 5.4 & 7.3 & 4.1 & 7.6 & 4.1 \\
\hline C.E.C. $\mathrm{cmol} \mathrm{kg}^{-1}$ & 56 & 107 & 66 & 106 & 37 & 18 & 280 \\
\hline Gross Ca & 265 & 0 & 0 & 127 & 0 & 3 & 0 \\
\hline Saturation $\%$ & 100 & 89.1 & 92 & 100 & 60 & 85 & 8.5 \\
\hline
\end{tabular}

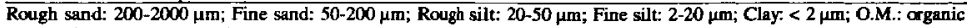
matter; C.E.C.: cationic exchange capacity.

\subsection{Experimental feature}

Primarily, equilibrium time was established with the LHA01, PAL01, TRI01 soils: five replicates of $2 \mathrm{~g} \mathrm{d.w}$. of soil were weighted in polyethylene batches. Osmosed water was added 24 hours before the contamination in order to allow soil-solution balancing. ${ }^{24 i} \mathrm{Am}$, as carrier-free americium nitrate in $1 \mathrm{~N}$ $\mathrm{HNO}_{3}$ was used. Each sample was spiked with a $200 \mu \mathrm{L}$ aliquot of $1000 \pm 10 \mathrm{~Bq}$, neutralized to pH 6.4 with $113 \mu \mathrm{L}$ of $1 \mathrm{M} \mathrm{Na} \mathrm{CO}_{3}$, immediately before addition to the batch; the final volume was adjusted to $\left.20 \mathrm{~mL}\left({ }^{241} \mathrm{Am} \text { concentration: } 0.39 \mu \mathrm{g} \mathrm{L}\right)^{-1}\right)$. Batches were squeezed by hand to obtain homogenous contamination of the samples. Then, samples were left, with periodical shaking by hand, at room 
temperature $\left(20^{\circ} \mathrm{C}\right)$ and $1 \mathrm{~mL}$ of each supernatant was sampled after $1,2,7,15$ and 30 days. The sampled solution was then hot-acidic mineralized. Measurements were performed by liquid scintillation and, where necessary, e.g. for samples under detection limits, by alpha spectrometry. At the end of the experiment, all containers and residual soils were measured to appreciate losses of radioactivity due to sorption on experimental devices. Sorption isotherms were afterwards determined in a similar manner with the following differences: a) soil was spiked with a range of ${ }^{241} \mathrm{Am}$ aliquots including 100,500 , 1000,5000 and $10000 \mathrm{~Bq}$. per sample and b) $1 \mathrm{~mL}$ of each supernatant was sampled after the equilibrium time previously determined. Samples were then treated and measured as described before.

\subsection{Data interpretation}

The sorption isotherms (massic activity sorbed on the soil vs volumic activity remaining in solution, $\mathrm{Bq} \mathrm{g}^{-1}$ per $\mathrm{Bq} \mathrm{mL} \mathrm{L}^{-1}$ ) were drawn and the experimental points fitted to a linear curve, the slope being the value of $\mathrm{Kd}$. Then the theoretical retention in soils was evaluated with the Baes and Sharp model classically used in assessment calculations $[20,21]$ and described thereafter:

$$
\begin{aligned}
& R=\frac{1}{\lambda_{r}+\lambda_{w}} \\
& \lambda_{w}=\frac{F e}{H \times(\theta+\rho \times K d)} \\
& C_{\text {soil }}(t)=C_{\text {soil }}(0) \times e^{-t / R}
\end{aligned}
$$

with:

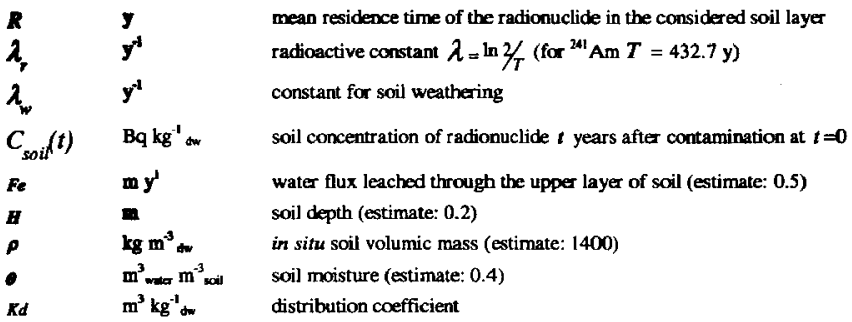

These categories of relationship are convenient for modeling, however they postulate implicit assumptions that controvert their validity; for instance, in contradiction with equation (2), it is likely that the $\mathrm{Kd}$ value varies as a function of the volumetric water content because as a soil dehydrates the aqueous phase in contact with the soil surfaces increases in the smallest pores and the ionic strength of the solution tends to extent closer to the clay surfaces.

\section{RESULTS AND DISCUSSION}

\subsection{Determination of Kd values}

The sorption of ${ }^{241} \mathrm{Am}$ on the soils begins rapidly; the equilibrium is expected to be achieved after 200 hours. At that time, more than $99 \%$ of the initial radioactivity is sorbed on the soil (Figure 1). The "sorption isotherms" are thus established for a contact time of 250 hours. 


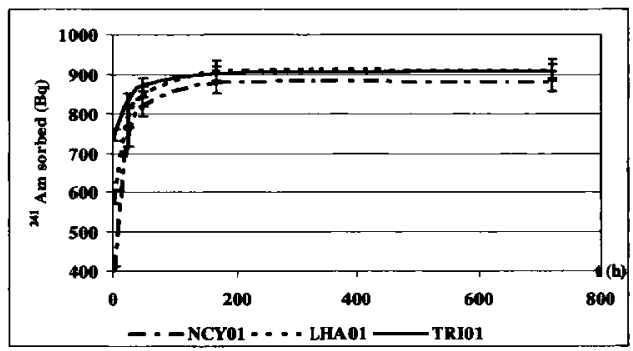

Figure 1: Determination of equilibrium time: radionuclide sorbed on the soils, vs contact time $f$. Batches of $2 \mathrm{~g} \mathrm{~d}$.w. of soil and $20 \mathrm{~mL}$ of solution spiked with $1000 \mathrm{~Bq}$ of ${ }^{241} \mathrm{Am}$ at $t=0$. Fixation on the bucket is $117+23 \mathrm{~Bq}$.

An example of the curves that were obtained for each soil is shown (Figure 2). The constant slope suggests that the number of available sorption sites remains constant throughout the whole range of concentrations and attests that the saturation is not reached. This model explicitly considers dependency of the partition coefficient on the solution concentration of ${ }^{241} \mathrm{Am}$ only and neglects dependence on other parameters that can influence adsorption. The $\mathrm{Kd}$ values are equal to the slope of the line fitted to the experimental points (Table II). These results are consistent with default values usually applied in risk assessments and with the general known behaviour of americium in soil: a high positive correlation $\left(R^{2}=\right.$ 0.967) of Kd values $v s \mathrm{pH}$ is observed except for the very specific TH1 soil. In this case, we can suppose that the complexation of the radionuclide with the organic matter is so important that it masks any other soil parameters' influence.

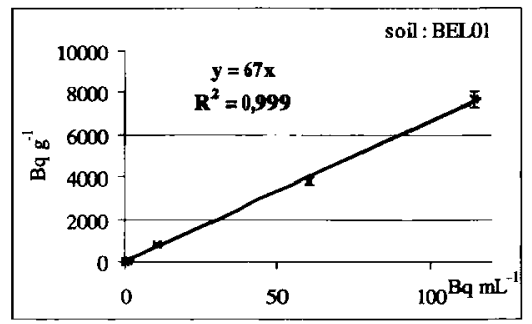

Figure 2: Example of sorption isotherm: experimental points and linear adjustment.

Table II: ${ }^{241}$ Am distribution coefficient $\mathrm{Kd}$ (arithmetic mean \pm standard deviation), in Bq $\mathrm{kg}^{-1}{ }_{\text {dry soil per } \mathrm{Bq}} \mathrm{m}^{-3}$ soil solution, for a contact time of $250 \mathrm{~h}$. Experimental points fit a linear regression; the correlation coefficient $\mathbf{R}^{2}$ is indicated in italic letters.

\begin{tabular}{cccccccc}
\hline Soil & BELO1 & LHAO1 & PALO1 & NCYO1 & TRIO1 & CADO1 & THI \\
\hline Kd & $67 \times 10^{-3}$ & $411 \times 10^{-3}$ & $988 \times 10^{-3}$ & $2691 \times 10^{-3}$ & $2695 \times 10^{-3}$ & $4103 \times 10^{-3}$ & $8204 \times 10^{-3}$ \\
& $\pm 5 \times 10^{-3}$ & $\pm 28 \times 10^{-3}$ & $\pm 188 \times 10^{-3}$ & $\pm 585 \times 10^{-3}$ & $\pm 1100 \times 10^{-3}$ & $\pm 1140 \times 10^{-3}$ & $\pm 63 \times 10^{-3}$ \\
\hline$R^{2}$ & 0.999 & 0.999 & 0.996 & 0.953 & 0.90 & 0.986 & 0.976 \\
\hline
\end{tabular}




\subsection{Evaluation of ${ }^{2+1} \mathrm{Am}$ residence time in soils}

The mean ${ }^{241}$ Am residence time is evaluated (equation 1) using either the experimentally measured Kd values (Table II) or the default values chosen according to their corresponding "soil type" [20, 19]; experimental and theoretical values are then compared (Table III). Depending on the soil, there may be large differences between both results, most of experimental values being lower than the default ones. This may be attributed to the fact that the definition of the theoretical soil types, mainly based on textural criteria, are poorly adapted to americium, the behaviour of which depends more on other soil parameters than on its texture.

Table III: Residence time of ${ }^{241} \mathrm{Am}$ in soil, evaluated from either experimental data or generic (default) values.

\begin{tabular}{cccc}
\hline Soil & $\begin{array}{c}\text { Residence time calculated from } \\
\text { experimental Kd } \\
(\mathrm{y})\end{array}$ & $\begin{array}{c}\text { Theoretical soil type } \\
\text { and corresponding default Kd } \\
\left(\mathrm{m}^{3} \mathbf{k g}^{-1}\right)\end{array}$ & $\begin{array}{c}\text { Theoretical residence time } \\
\text { calculated trom defaut Kd } \\
(\mathbf{y})\end{array}$ \\
\hline BEL01 & 38 & sand $(2.0)$ & 1120 \\
NCY01 & 151 & clay $(8.1)$ & 4536 \\
LHA01 & 230 & loam $(0.99)$ & 555 \\
PAL01 & 553 & loam $(0.99)$ & 555 \\
TR101 & 1509 & clay (8.1) & 4536 \\
CAD01 & 2298 & loam (0.99) & 555 \\
TH1 & 4594 & organic (110) & 61600 \\
\hline
\end{tabular}

In order to evaluate the importance of sclecting a particular value of $\mathrm{Kd}$, we used equations (1-3) to determine the significance of modifying $\mathrm{Kd}$ on the ratio $C_{\text {soil }}(t) / C_{\text {soil }}(0)$ for $t$ varying from 10 to 500 years (Figure 3). For a given isotope, and thus a given radioactive decay, the importance of $\mathrm{Kd}$ depends not only on $t$ value, but also obviously on the range of $\mathrm{Kd}$ itself: for instance, in the case of ${ }^{241} \mathrm{Am}$, for $t=10 \mathrm{y}$, using an overestimated $\mathrm{Kd}$ value $\left(\mathrm{m}^{3} \mathrm{~kg}^{-1}\right)$ of $10^{-1}$ instead of $10^{-2}$ overestimates approximately five times the ratio $C_{\text {soif }}(10) / C_{\text {soil }}(0)$, but using a $\mathrm{Kd}$ of 10 instead of 1 has rather no influence on this ratio.

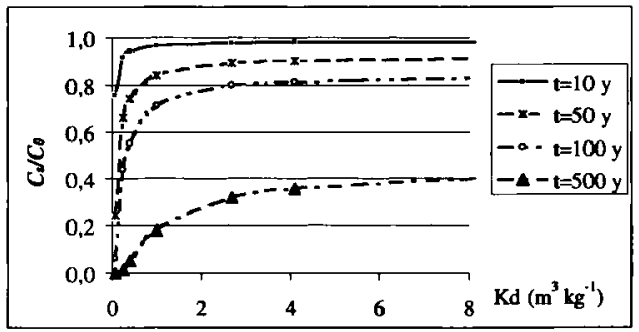

Figure 3: Variation of $C_{\text {soil }}(t) / C_{\text {soll }}(0)$ evaluated with equations (1-3), function of ${ }^{241} \mathrm{Am} \mathrm{Kd}$ values, different times after contamination.

\section{CONCLUSION}

Generic or default partition coefficient values can result in significant uncertainties when predicting the impact of radionuclide migration. Using more suitable $\mathrm{Kd}$ values is more important for radiosotopes with 
longest radioactive period. For a given radioactive decay, the weight of Kd increases with the time scale considered and also when soils exhibit low distribution coefficients. Therefore, depending on these three main circumstances, partition coefficient values measured on site-specific soil are either wanted or not needed at all, for improved assessments. This supposes anyway that the simplified models using the $\mathrm{Kd}$ for evaluating the radionuclide retention time in soil can be appropriate regarding the aim of the evaluation. Intrinsic limits to the Kd concept, measurement and utilization favor the wish of mechanistic or semi-mechanistic models that would explicitly accommodate the dependency of radionuclide sorption on true chemical speciation. But, to be operational, these means require intensive modelling attempt sustained by a large data collection effort that will unlikely be possible in the immediate future.

\section{Acknowledgments}

The authors are grateful to P. Hurtevent and M. Morello (IPSN, Cadarache) for technical realization.

\section{References}

[1] Delguedre C., Ulich H.J. and Silby H., Radiochim. Acta 65 (1994)173-179.

[2] Fanghaenel T., Weger H.T., Schubert G. and Kim J.I., Radiochim. Acta 82 (1998) 55-58.

[3] Geckeis H., Klenze R. and Kim J.I., Radiochim. Acta 87 (1999) 13-22.

[4] Kim J.I., Rhee D.S., Buckau G. and Morgenstern A, Radiochim. Acta 79 (1997) 173-181.

[5] Labonne-wall N., Moulin V. and Vilarem J.P., Radiochim. Acta 79 (1997) 37-49.

[6] Hummel W., Glaus M.A., Van Loon L.R., Appl. Geochem. 15 (2000) 975-1001.

[7] Jacquier P., Meier P. and Ly J., Appl. Geochem. 16 (2001) 85-93.

[8] Carlsen L., The role of organics on the migration of radionuclides in the geosphere EUR- 12024 (CCE, Brussels 1989) pp. 40-44.

[9] Fleury C.P., Goudard J.and Durand F.P. Effects of humic substances on the migration of radionuclides: complexation and transport of actinides. EC Project-First technical progress report (CCE, Brussels, 1988) pp. 147-159.

[10] Livens F.R. and Singleton D.L., J. Environ. Radioactivity 13 (1991) 323-329.

[11] Moulin V. and Moulin C., Appl. Geochem. 10 (1995) 573-580.

[12] Roussel-Debet S., Colle C., Hurtevent P. and Morello M., Radioprotection 35 (2000) 367-380.

[13] Takahashi, Y., Minai Y. and Kimura T., Material Res. Soc. 353 (1995) 189-197.

[14] Keith-Roach M.J., Day J.P., Fifield L.K., Bryan N.D. and Livens F.R., Environ Sci. Technol. 34 (2000) 4273-4277.

[15] Bundt M., Albrecht A., Froidevaux P., Blaser P. and Flühler H., Environ. Sci. Technol. 34 (2000) 3895-3899.

[16] Mboulou M.O., Hurtgen C.H., Hofkens K and Vandecasteele C., J. Environ. Radioactivity 39 (1998) 231-238.

[17] Nisbet A.F., Shaw S., and B. Salbu, J. Environ. Radioactivity 18 (1993) 71-84.

[18] Cawse P.A. and C. Colle,"Variability in soil to plant transfer of Np, Am and Cm" VI report of the working group soil- to plant - Rivm (UIR eds, Bilthoven, Netherland, 1989) pp. 22-35.

[19] Thibault D.H. and M.I. Sheppard, A critical compilation and review of default solid-liquid partition coefficients $\mathrm{Kd}$ for use in environmental assessment. AECL-10-125-RO-1L0, (Whiteshell, Canada, 1990) pp. 54-56.

[20] I.A.E.A., Handbook of parameters values for the prediction of radionuclides transfer in temperate environments. Technical report series $N^{\circ} 364$, (LAEA, Vienne, 1994) pp. 30-31.

[21] Sheppard M.I., Elrick D.E. and Peterson S.R., Can. J. Soil Sci. 77 (1997) 333-344. 